\title{
Motivating \& Managing Knowledge Workers: Evidences from Diverse Industries \& Cultures
}

\author{
Ik. Muo ${ }^{1}$ \\ ${ }^{1}$ Department of Business Administration, Olabisi Onabanjo University, Ago-Iwoye, Ogun State, Nigeria \\ Correspondence: Ik. Muo, Department of Business Administration, Olabisi Onabanjo University, Ago-Iwoye, \\ Ogun State, Nigeria. E-mail: muoigbo@yahoo.com
}

\author{
Received: October 5, 2012 Accepted: November 19, 2012 Online Published: March 13, 2013 \\ doi:10.5539/jms.v3n2p119 URL: http://dx.doi.org/10.5539/jms.v3n2p119
}

\begin{abstract}
This paper reviews existing literature on motivation and knowledge work, and empirical studies in different environments and industries on knowledge work and worker. It also surveys 150 Nigerian knowledge workers with diverse characteristics. It holds that the optimal strategies for managing and motivating knowledge workers are job redesign to increase the intrinsic motivational value of the jobs; competitive financial rewards, empowerment and flexibility, equity, fairness, respect and regard; a conducive environment that would enable them to bloom and exercise their intellect unhindered, including making mistakes and learning from it in a connected organisation; leadership practices that are responsive to their peculiarities; a leader that is a coach, mentor and enabler and who should be able to convincingly explain why a knowledge worker should agree to be managed by him, and an organizational structure that is devoid of undue bureaucracy and protocols and frees them for optimal performance.
\end{abstract}

Keywords: managing, motivation, retention, knowledge work (KW), knowledge worker (KWrs)

\section{Introduction}

The four central issues in organisations are objectives, resources, input-output process (work) and the environment. An organization is a legal entity established to achieve specified objectives through the optimal utilization of resources and management of the input-output process. This it does within the environment. But the only way to achieve these objectives -whatever they are- is to make a minimum level of profit which will enable it to continue to be in business by least maintaining its wealth-creating abilities. And it can make this profit only through mutually beneficial exchanges with customers. Customers thus become another critical factor.

Generally, every organization consists of these tangible and intangible elements: the environment, vision \& mission; values, objectives, strategy, authority, work, people and other resources (land, labour capital, entrepreneurship and technology, especially, ICT) The only living thing among these elements are the human beings, who have entered into contractual relationships with the organization to offer their human endowments in exchange for some forms of rewards. The people in the organization thus become the most critical factors of production because they coordinate other resources and they have the will and discretion in deciding if, when and how to work. The concern of managers right from days of industrial revolution and emergence of formal organisations has been how to ensure that workers put in their best and that their best is good enough. In effect, there are two major challenges: how to ensure that the workers are committed to organizational goals and are working towards those goals to the best of their abilities. These two challenges are complicated by the fact that the workers have different needs, which also vary with time (Muo, 2007, 197).

This is the challenge of motivation within organizations. Motivation is one of the greatest challenges facing managers across the globe because it influences workers' performance and thus the extent to which organizations are able to achieve their objectives and justify their existence. This challenge has further been complicated and compounded by the emergence of knowledge workers (KWRs); people who use their brains or 'embedded intellectual content' to create extraordinary value for the organization and its stakeholders. These educated, knowledgeable, versatile and confident workers know their worth and even in a country like Nigeria with an employers' market, they expect respect and recognition from the organizations and their leaders. 
The objective of this paper is to discuss the challenges and techniques for managing and motivating knowledge workers (KWrs) in diverse industries and cultures. It is divided into five parts. In addition to this introductory part, part two delves extensively into the issue of motivation, the nature and scope of knowledge work as well as the peculiarities of knowledge workers; Part 3 explains the methodology for the study part four examines the various strategies for optimally managing motivating and retaining KWrs workers while the paper is concluded in part five.

\section{Theoretical and Conceptual Clarifications}

\subsection{Motivation}

\subsubsection{The Nature of Motivation}

Motivation is goal-directed behaviour. It starts with deficiency (needs) which activates behaviour (drives) aimed at the goals (that which can alleviate the deficiency) (Luthans, 2005). These three interdependent elements: Needs, Drives and Incentives (or Goals.) are thus central to a proper understanding of motivation. When needs arise, drives energise the person towards goals which will satisfy those needs and restore equilibrium. Motivation is also the inner force that accounts for the intensity, (how hard one tries); direction (the focus of the effort) and persistence(how continuously one tries) of a person's efforts towards attaining a goal or a basket of goals (Ivancevich \& Matteson, 2002).

Motives may be primary, secondary or general. Primary needs are natural and physiologically based eg hunger, thirst, sleep, pain-avoidance. Secondary motives have the most predominant impact on human behaviour. They are learned and as societies develop, they override the primary motives. Secondary motives include need for achievement, power, security and status (Yukil, 1990; Luthans, 2005). General motives exist in the gray area between primary and secondary and they are neither learned nor physiologically based. They tend to generally increase tension or stimulation and examples are curiosity, and manipulation. Some motives cut across categories. Affection for instance is a primary, secondary and general motive.

Over the years several conceptual perspectives have been adopted in trying to explain why and how people are motivated. (Feldman, 2002). The Instinct Approaches hold that people are born with preprogrammed instincts that channel behaviour to desired directions. The Drive-Reduction Approaches hold that when people lack basic biological requirements a drive is produced to obtain that requirement. The Arousal Approaches hold that we seek to maintain a given level of stimulation and activity and that we behave to reduce or increase that level whenever the need arises. Incentive Approaches posit that we are motivated by our desire to obtain valued external goals while the Cognitive Approaches argue that motivation is a function of people's thoughts, expectations and goals which are intrinsic and extrinsic.

\subsubsection{Theories of Motivation}

Theories of motivation have been traditionally grouped into those that try to identify what motivates people (Content Theories) and those that concentrate on how motivational choices are made (Process Theories). Emerging theories include Control Theories (concerned with the motivational impact of the degree to which workers perceive themselves to be in charge of their lives or jobs) and the Agency Theories (which are concerned with the motivational value of the divergence or convergence of interest between the principlas-the firm- and their agents-the workers). Some of these theories are discussed hereunder.

Hierarch of Needs Theory (Maslow, A.H, 1943) posits that human needs are arranged in hierarchical order, that each is operational at a given time and that a satisfied need does not motivate. These needs are Physiological, Safety and Love as well as the need for Self Actualisation, the need to become everything that one is capable of becoming (Maslow, 1943:370). Two additional needs which even Maslow himself gave relatively little attention are the Cognitive Needs (the desire to know and the desire to understand) and the Aesthetic Needs (a craving for beauty in ones surroundings).

Maslow divided these needs into deficiency and growth needs, with self-actualisation being the key growth need which is never fully satisfied and thus a permanent source of motivation. The potency of these needs may shift forth and back under different circumstances. For instance, during bad economic times, physiological and safety needs tend to dominate individual behaviour while in good economic times, higher order needs may dominate (Rue \& Byars, 1977:199). The theory also acknowledges some exceptions: some people may prefer self-esteem to love and for others higher-order needs may become operational before the satisfaction of basic needs while some may have lost the urge for the higher needs (Mullins, 1996:490). 
ERG Theory (Alderfer Clayton) is a major modification of Maslow's Theory which categorized the needs into three: Existence; Relatedness and Growth and that these needs are not hierarchically arranged; any need can become operational at any time

The three major variables in Equity Theory (ADAMS; J.S.1961) are: Inputs, Outcomes and the Reference Person. He argues that inequity exists when a person's input/outcome ratio is significantly different from that of a reference source while equity on the other hand exists when the two ratios are equal. Inequity (whether positive or negative), results in dissatisfaction in the form of anger (under-reward) or guilt(over-reward)

Goal-Setting Theory (Locke,1966) focuses on how goal-setting and related factors (participation, acceptance and difficulty) affect performance. It holds that goal setting is positively related to performance, that goal specificity, difficulty and feedback enhance performance. Goal content and intensity exert directive influence, regulate energy expenditure, and influence the level/direction of effort and that Goal achievement leads to satisfaction while failure leads to dissatisfaction

In Theory X and Theory Y (Douglas McGregor; 1957 \& 1960), McGregor argues that management assumptions about the control of human resources determine the quality of the enterprise and that existing assumptions were counterproductive. Those existing assumptions (Theory X) are that that people dislike work and prefer to be directed. This mindset is more appropriate for children and is counterproductive to the realization of human potentials. He argues for a new set of assumptions and practices attuned to the higher order needs. This is Theory $\mathrm{Y}$ which holds that work is natural, that coercion is not the only way to induce performance, that commensurate reward leads to commitment and that people can accept and even seek responsibility when the conditions are right. Theory $\mathrm{Y}$ is a new paradigm of respect and dignity for the worker and proposes integration of organizational and personal goals, participative management and a relationship between the manager and his subordinate under the envisaged culture that is one of a teacher, professional helper, colleague and consultant (McGregor, 1960:45)

Other theories include Mclleland's Achievement Theory which states that people are propelled by the need for achievement (n' Ach) power affiliation and fear of failure. Those who have high n'Ach are characterized by moderate risk-taking, need for immediate achievement, satisfaction with accomplishment in itself, amongst others. The VIE (expectancy) Theory Championed by Victor Vroom, holds that motivation occurs when a staff believes that efforts would lead to performance(expectancy), and that performance would lead to valued rewards (instrumentality and valence). Herzberg's Two-Factor Theory proposes that there are hygienic factors, related to the job context which do not motivate but can cause disaffection if not properly handled (salary, working conditions, and relationship with peers etc). The second group of factors, which actually motivate include achievement, recognition, work itself. He therefore suggested job enrichment as a strategy for increasing the motivators at work as against the hygienic KITA (Kick in the Arse) elements (Herzberg, 1968)

\subsubsection{Money, Motivation \& Behavioral Consequences of Compensation}

Right from the days of Taylor and his scientific management mentality, money has always been seen as the greatest motivator for workers. Of course this has to be so in a situation where money is the only means to acquire whatever one wanted/wants. The motivational value of money is invariably high in countries like Nigeria because of the circumstances-mass poverty, lack of basic amenities which turns everyone into his own municipal government, corruption. Opashl \& Dunnette, (1966:94) highlight the motivational roles of money as follows: Money is a Generalized Conditioned Reinforcer because it is usually paired with primary reinforcers; a Conditioned Incentive because the repeated pairing of money with primary incentives establish a new learned drive for money; an Anxiety Reducer because people become anxious in the absence of money; a Hygiene Factor because it serves as a potential dissatisfaction if not sufficiently available and an Instrument For Gaining Desired Outcomes because it helps to acquire other desired outcomes and while it has no value in itself, it but symbolizes intangible goals. They also argued that compensation policies, schedules of pay, secret pay policies and pay curves have motivational impacts depending on how they are applied. They conclude that personal characteristics of workers -preferences, opinions, perceptions-influence the workers response to the compensation package, which in turn lead to variations in these characteristics.

Money is thus a critical motivational variable. This is due to its five general roles already discussed. In addition to these generic roles, the features of the pay policies, the type of job, the personality of the individual workers and their preferences and perceptions also intervene in the motivational value of monetary compensation. In effect the pay itself, how it is administered and the peculiarities of the staff are all critical in determining the motivational roles of money. Other factors that would affect the extent to which money motivates include salary level, cost of living, level of education, family/ personal background and future expectations (Muo, 1999). 


\subsubsection{Motivation \& Performance}

Performance is affected by efforts, abilities, role characteristics, organizational support and other factors. The efforts of staff depend on motives, health, expectations, rewards and job satisfaction. Abilities may be technical, interpersonal, conceptual, emotional and cultural. Role characteristics refer to the extent of role clarity. Issues like role conflict, ambiguity and incongruence as well as overload and the workers perception of the roles become critical factors. The performance enhancing properties of goals include how they are set; the features and workers attitude towards them. Organisational support includes training, authority, and empowerment. Other factors include cultural variables, group performance and influence and industry norms. Blumberg and Pringle (1982:560) however developed a triangular model, which sees the critical factors influencing performance as individual attributes (ability to perform), work efforts (willingness to perform) and organizational support (the opportunity to perform). These three factors must mutually reinforce each other for meaningful performance.

\subsubsection{Culture \& Motivation}

Culture is an environment of human-created beliefs, customs, knowledge and practices and develops in each person, specific motivational patterns; 'configurations of many specific cultural influences that together determine the way individuals approach their jobs'. Davies (1977:24) There are 4 significant motivational patterns. These are achievement motivation: a desire to overcome challenges, advance and grow. People with this motivational pattern seek accomplishment for its own sake. Affiliation motivation: the drive to relate to people; the affiliation motivated fellow works harder when complemented for favourable attitude and cooperation and would select friends to surround him; competence motivation: people with this pattern are driven to do quality work and mostly interested in the technical aspects of their jobs. Power motivation: A power-motivated person seeks to be in control and is a higher risk-taker than others. Other motivational patterns identified by Davies include autonomy, security and status. Motivational patterns are not mutually exclusive and while a person may have elements of most of these patterns, one or two will be dominant. By identifying the operational motivational pattern, management will be able to separate staff who are self-motivated from those who are externally propelled and deal with them according to their motivational differences

\subsubsection{Motivation in Practice}

In the final analysis, motivation is about getting the best from the employees, a best that is good enough for the organization. This can only be achieved when the worker can achieve his personal goals by working for the achievement of the organizational goals. The organization should therefore match incentives with employee needs by offering what he needs or making him need what the organization can offer. Motivation is also a personal affair; nobody can motivate anybody else. What managers can do is to provide conducive environment to enable the workers motivate themselves. The essence of all the theories and analyses undertaken so far is to assist the organization in ensuring adequate motivation for the staff so that they work with commitment towards corporate goals. The various theories considered have given tips on how to motivate employees. Maslows theory emphasizes that the manager should ascertain a staff's current position on the hierarchy so as to determine what would motivate him; the goal-setting theory urges us to ensure that goals are properly set and that they have motivational features; McGregor encourages managers to treat workers with more respect and trust by adopting the Theory Y Paradigm while Herzberg urges managers to pay attention to motivational factors and avoid KITA tendencies.

Beyond the theories however, getting the best from staff involves recruiting/selecting qualified staff, describing the job clearly for them, training and equipping them and providing a conducive environment: physical environment, organizational climate, leadership style, adequate stock of social capital, ambience and lighting. These five conditions can be seen as the foundation for effective motivational strategies. In their absence, no effort at motivation would yield fruit. To these primary issues are added challenging and rewarding jobs, recognition, responsibilities and opportunities for growth, fair appraisal (ethical and objective) performance-reward parity, equity in the workplace, suitable organizational culture, appropriate goals, incentives and feedback, participatory management, clarity as regards work expectations, authority and standards, supportive superiors, and open communication so that everybody knows what is happening at any point in time.

\subsection{Defining Knowledge Work \& Knowledge Worker}

It is believed that the late Peter Drucker was instrumental for the development of the concepts of knowledge work (KW) and knowledge worker (KWr) He conceptualised the KWr as one who uses 'what he has between his ears ... knowledge, theory and concept, rather than physical force or manual work' (1967:3) and further clarified that KW is defined by its results (1967:7), not by quantity or its costs. Simply, KW involves the exertion of intellect (brains) as against physical capabilities (brawn); and a $\mathrm{KWr}$ is somebody involved in $\mathrm{KW}$. Ware \& 
Grathan (2007:1) see KWRs as using their cognitive skills to solve complex problems while Davenport (2006) emphasizes that their primary function is related to knowledge. From a Nigerian perspective, Oboh (2010:13) differentiates a problem solver from a production (manual) worker; someone who uses knowledge and information to deepen existing knowledge and information and ends up processing uncodified knowledge which is difficult to duplicate'

Olomolaiye \& Egbu (2004:1) describe KWrs as those who receive information, assimilate it, decide what to do and execute the relevant decisions. These problem solvers, who use their intellect rather than their manual skills to earn a living, require high level of autonomy, and are very interested in the quality of their judgment rather than the speed of work. They also have more allegiance to their area of expertise than to their employers, cherish challenging tasks and require a habit of continuous learning due to their recognition of the shelf-life of knowledge. They possess uncodified knowledge which is difficult to duplicate and the source of this knowledge is between their ears (Western Management Consultants, 2002). To Vogt (1995), KWrs have the capacity to co-create and communicate new insights and involved in non-repetitive duties characterised by continuous learning, intuition, new mindsets and imagination. Because they work in problem-solving teams rather than tackling routine tasks, organizations core competences reside in them and they are thus very essential to the long-term success (Howrtz et al, 2003:23) The KWr concept, according to Alvesson (2000) contains contrasting attributes like working with ambiguity-intensive information and being required to deploy personal knowledge and having high cognitive power and abstract reasoning.

There are several levels and layers of KWr and that is why Ware \& Grathan (2007:4) categorise them into knowledge executors (who apply existing knowledge to solve routine problems) and knowledge generators (who create new knowledge to develop new solutions or concepts). $\mathrm{KW}$ is diverse and includes individuals in traditional professions (law, medicine), executives in marketing, strategy, consulting) and specialized knowledge-based jobs(pilots, musicians, bureaucrats). Even jobs that were hitherto low on the knowledge spectrum are becoming KWs through the instrumentality of ICT. Quinn et al (1996:71) who use the term 'professional intellect' argue that KWrs create most of the values in today's economy and define the layers of KW as:

- Cognitive knowledge (know what) basic mastery acquired through extensive training.

- Advanced Skills (know-how) ability to apply the rules of the discipline into real-world problems.

- Systems understanding (know-why) deep knowledge of the web of cause and effect relationships underlying the discipline used to create extraordinary value.

- $\quad$ Self-motivated creativity (care-why) will, motivation and adaptability for success.

Gofee \& Jones (2007:72) describe them as clever, handful of people who produce disproportionate value from the resources available to them. They identify the characteristics of these Clever People that also make them difficult to manage as: they know their worth; their skills are not easily transferable; they ignore corporate hierarchy and promotions do not excite them even though they care about titles, they expect instant access, they are well connected-to a well developed knowledge network. Who they know is more important than what they know. This increases their value and their flight risks; they have low boredom threshold: if they are not engaged intellectually or inspired with organizational purpose, they exit and they won't thank you: they feel they shouldn't be led and even when you are leading them well, they will be unwilling to recognize your leadership

There are other characteristics of knowledge workers that impact on their management and motivation. Some knowledge workers are also in money (Wetlaufer, 2000:53); they are mobile and they do leave-very readily (Serrat, 2008:4) and they reject and detest the traditional command and control culture and want self control and autonomy. They also want to be part of strong communities characterized by design, story, meaning, play, humour and lightheartedness (Grantham \& Ware, 2007; Pink, 2005). They request for work that delivers constant stream of growth and challenge, firms that are winning continuously and bosses that are more engaged with the work and build healthy, productive work culture. KWrs want to be respected by the people they work for and they are independent agents who want their bosses to get out of the way; they want to build a dream and make a difference (Wetlaufer, 2000:53) In terms of specifics, the 2010 best job compendium (CNN Money.com in partnership with Payscale.com) is a list of high flying KW across the globe: software architecture, medicine, management consulting environmental and civil engineering, database administration, biomedical engineering, risk management health care consulting, information system security engineering. 


\section{Methodology}

The approach to this study is dualistic. In the first instance, there was a review of empirical studies from across the globe and diverse industries like computer and ICT, construction, manufacturing, R\&D, electronics and the professions like law. There was also an empirical study of a cross section of KWR in Nigeria which was specifically designed to elicit a ranking of the relevant motivational variables. The theories and empirical studies reviewed and the empirical work done in Nigeria formed the bases of the discussions and conclusions

\section{Managing \& Motivating Knowledge Workers}

\subsection{Knowledge Workers: Their Importance \& Need for Special Motivational Efforts}

KWrs have overrun the economic environment once dominated by laborers, technical, professional and managerial people because knowledge is the key driver of competitive advantage. Drucker (1993) asserts that KWrs differ from the previous generations of workers because they own the means of production. Performance thus depends on their motivation and retention. Furthermore, they possess tacit knowledge which is almost impossible to articulate because of its immobility and rarity. Grant (1996) identify tacit knowledge as the most strategically significant resource especially if the firm can translate it into improved competencies, capabilities, processes, and products. KWrs are indeed, capital, not labor (Drucker, 2002). Furthermore, a complex dual-dependent relationship has emerged as management needs to meet the expectations of KWrs who in turn depend on the firm for development of contextual and new knowledge (Jayne, 2006:1). Firms also continuously seek to communalize the intellect the KWrs for organisational goals and that is why they are retained even during economic downturns as failure to do so may undermine competitive superiority and institutional memory in future. Olowolaive \& Egbu (2004:5) highlight the benefits accruable to an organization for motivating KWrs as their innovativeness, performance and efficiency gains, loyalty and lower labour turnover, dispersal of best practices and optimal knowledge sharing environment.

\subsection{The Best Motivational Package? Find Out From Them!}

\subsubsection{What Employees Need versus What HR Staff Think They Need}

It is commonsensical to state that the best way to find out what motivates anybody is to 'negotiate direct'! It is important to ascertain what exactly the workers want especially as these preferences are moving targets and change regularly due to individual and workforce changes. This is very important because what the workers want is miles apart from what HR executives think the workers want (Babcock, 2005). A 2004 study by Society for Human Resources Management \& financial news arm of CNN news group (CNNfn) indicates that out of 21 potential motivators, HR managers and staff agreed on the rating of only one and differed widely on the rest (see Table 1).

Table 1. Relative ranking of motivational factors by employees \& HR professionals

\begin{tabular}{|c|c|c|}
\hline Rank & According to Employees & According to HR professionals \\
\hline 1 & Benefits & Relationship with immediate supervisor \\
\hline 2 & Compensation/pay & $\begin{array}{l}\text { Management recognition of employee job } \\
\text { performance }\end{array}$ \\
\hline 3 & Feeling safe in the work environment & Benefits \\
\hline 4 & Job security & $\begin{array}{l}\text { Communication between employees and senior } \\
\text { management }\end{array}$ \\
\hline 5 & Flexibility to balance work/ life issues & Compensation pay \\
\hline 6 & $\begin{array}{l}\text { Communication between employees and senior } \\
\text { management }\end{array}$ & Opportunities to sue skills/abilities \\
\hline 7 & Relationship with immediate supervisor & Flexibility to balance work/life issues \\
\hline 8 & $\begin{array}{l}\text { Management recognition of employee job } \\
\text { performance }\end{array}$ & Career development opportunities \\
\hline 9 & Opportunities to use skills/abilities & Job security \\
\hline 10 & The work itself & $\begin{array}{l}\text { Organizations commitment to professional } \\
\text { development }\end{array}$ \\
\hline 11 & Overall corporate culture & Job-specific training \\
\hline 12 & Autonomy and independence & Career advancement opportunities \\
\hline 13 & Career Development opportunities & Feeling safe in the work environment \\
\hline 14 & Meaningfulness of the work & The work itself \\
\hline
\end{tabular}




\begin{tabular}{|c|c|c|}
\hline 15 & Variety of work & Relationship with coworkers \\
\hline 16 & Career advancement opportunities & Overall corporate culture \\
\hline 17 & $\begin{array}{l}\text { Contribution of work to organizational business } \\
\text { goals }\end{array}$ & Autonomy \& independence \\
\hline 18 & $\begin{array}{l}\text { Organizations commitment to professional } \\
\text { development }\end{array}$ & $\begin{array}{l}\text { Contribution of work to organization business } \\
\text { goals }\end{array}$ \\
\hline 19 & Job-specific training & Meaningfulness of work \\
\hline 20 & Relationship with co-workers & Variety of work \\
\hline 21 & Networking & Networking \\
\hline
\end{tabular}

Source: Babcock, P. (2005) Find out what the workers want HR Magazine, Vol 50, No 4; April; p 53.

\subsubsection{The Nigerian Experience}

As a part of this study, efforts were made to find out from the KWrs what motivational variables appeal to them. Out of the 150 returned questionnaires, $30 \%$ are respondents from the banking and finance industry while $36 \%$ are in 'others'; $73 \%$ in wholly Nigerian owned concerns, most of the respondents are aged between 31 and 50 years $(80 \%)$ most hold first degree or equivalent $(75 \%)$, most are accountants $(30 \%)$ and $62 \%$ of them estimate that the percentage of knowledge workers in their organizations is above $31 \% .70 \%$ of the respondents report that there are separate compensation packages between knowledge workers and others in their places of work while $80 \%$ believe that there is need for such differential

Table 2. Rating of motivational variables by Nigerian knowledge workers

\begin{tabular}{lllllllllll}
\hline & $\mathbf{1}$ & $\mathbf{2}$ & $\mathbf{3}$ & $\mathbf{4}$ & $\mathbf{5}$ & $\mathbf{6}$ & $\mathbf{7}$ & $\mathbf{8}$ & $\mathbf{9}$ & $\mathbf{1 0}$ \\
\hline Financial Rewards & $40 \%$ & $7 \%$ & $12 \%$ & $10 \%$ & $15 \%$ & $1 \%$ & $8 \%$ & - & $1 \%$ & $6 \%$ \\
Training \& Professional Development & $50 \%$ & $20 \%$ & $10 \%$ & $3 \%$ & $12 \%$ & $3 \%$ & $3 \%$ & $3 \%$ & $3 \%$ & $3 \%$ \\
Empowerment \& Flexibility & $32 \%$ & $6 \%$ & $14 \%$ & $12 \%$ & $12 \%$ & $4 \%$ & $4 \%$ & $11 \%$ & $3 \%$ & $2 \%$ \\
Equity \& Fairness & $18 \%$ & $4 \%$ & $6 \%$ & $14 \%$ & $14 \%$ & $16 \%$ & $10 \%$ & $8 \%$ & $4 \%$ & $6 \%$ \\
Innovative environment & $15 \%$ & $8 \%$ & $2 \%$ & $14 \%$ & $14 \%$ & $6 \%$ & $17 \%$ & $3 \%$ & $3 \%$ & $18 \%$ \\
Sense of belonging & $18 \%$ & $9 \%$ & $6 \%$ & $12 \%$ & $14 \%$ & $10 \%$ & $12 \%$ & $1 \%$ & $12 \%$ & $6 \%$ \\
Supportive superiors & $17 \%$ & $6 \%$ & $6 \%$ & $1 \%$ & $12 \%$ & $6 \%$ & $10 \%$ & $16 \%$ & $6 \%$ & $20 \%$ \\
Teamwork, affiliation \& attachment & $10 \%$ & $12 \%$ & $8 \%$ & $8 \%$ & $10 \%$ & $18 \%$ & $9 \%$ & $12 \%$ & $6 \%$ & $7 \%$ \\
Freedom of choice & $20 \%$ & $1 \%$ & $8 \%$ & $6 \%$ & $9 \%$ & $12 \%$ & $10 \%$ & $15 \%$ & $2 \%$ & $17 \%$ \\
Exploration \& professional & $25 \%$ & $3 \%$ & $3 \%$ & $6 \%$ & $12 \%$ & $15 \%$ & $2 \%$ & - & $12 \%$ & $22 \%$ \\
independence & & & & & & & & & & \\
\hline
\end{tabular}

From the above table, the rating of the motivational variables by Nigerian KWrs is as follows:

1) Training \& professional development (50\%)

2) Financial rewards (40\%)

3) Empowerment \& flexibility (32\%)

4) Exploration and professional independence (25\%)

5) Freedom of choice (20\%)

6) Equity and fairness and Sense of belonging (18\%)

7) 8. Supportive superiors (17\%)

8) 9. Innovative environment (15\%)

9) 10. Teamwork, affiliation and attachment $(10 \%)$

Thus while the US workers rated benefits as the highest, Nigerians rated it second and the Nigerian sample rated training and development first, a variable rated 13 out of 20 by the US respondents.

Thus in practical terms, these are the variables that are close to the hearts of Nigerian KWrs. The preeminence position attached to training and development is in tandem with theoretical and empirical evidences. In most surveys, training appears among the top three benefits sought by employees because they want the opportunities to learn and grow and they search for organizations that will facilitate their professional growth. Top 
professionals, technical employees and those under 30 tend to put developmental opportunities as their topmost priority (Pfau \& Kay, 2002). Even Maslow supports training as a motivational factor for KWrs because the self-esteem (ego) needs, can only be achieved when the staff is trained which will enhance self confidence, independence and professionalism and enjoy the confidence of others. The same goes for self actualization, because training and development enable the staff to enhance his competence.

The lower ranking of some intrinsic needs like freedom of choice and equity can also be explained in terms of the cultural and environmental realities. As Daft (2010) argues, there is need to fit incentives with culture. Thus while base pay is considered more important in the US, career opportunities have higher currency in Brazil; in China, it is the chance to learn and in Spain, work-life balance. It has also been revealed that intrinsic factors are less effective in economically disadvantaged countries with poor welfare system like Nigeria and high power-distance countries (Huang \& De Vliert, 2003). It has also been established that in Africa, showing respect for the individual and interest in his/her off-work needs and interests is motivational (Caudron; 1995)

\subsection{Evidence from Other Empirical Studies}

\subsubsection{A study of Computer Professionals}

A survey of the computer industry by Couger \& Zawaki (1983) reveal two characteristics of computer professionals that require special management action: low social need and high growth need. In addition, due to scarcity of qualified personnel, they are more vocal (the risk of retribution is low), impatient about promised changes and more loyal to the profession rather than to the organization. The study adopted the Job Diagnostic Survey developed by Hackman Oldham (1971) which was modified to include employee perception of relative importance of problems relating to maintenance, access to the computer, supervisors and others, objective setting and relative importance of 8 categories of compensation. The summary of their findings are:

- GNS (Growth Need Strength) is high for Data Processing professionals compared to others; they also have the lowest SNS (social need strength).

- $\quad$ The employees surveyed believed that feedback should be improved.

- Job redesign can increase satisfaction and productivity.

- Productivity improvement consists of two parts: improving techniques and improving motivation to use the techniques. Enormous time, energy and efforts have gone into the first part but little attention has gone into the second part.

- Work redesign can help individuals regain the kick that comes from doing a job well and encourage them to care enough about their work to develop the competencies to do even better. This is the type of satisfaction that develops only when an individual is stretching and growing as a human being and increasing his sense of competence and worth (Hackman: 1985, 138).

\subsubsection{Cultural Differences in Motivating Knowledge Workers}

A survey by Ingo \& Fiona (2007) involving about 900 lawyers in a multinational law firm illuminates the differences in motivation and perception across the cultural divide. They report that to motivate the lawyers to share knowledge, variables like career prospects, authority, provision of charge codes, recognition among peers or one-time incentives have very diverse impacts around the world. It was about the first major study into the motivation of global knowledge workers in the professional services.

\subsubsection{Motivating Knowledge Workers in the Construction Industry}

Olomolaiye \& Egbu (2004:1) examine the roles of pay, praise, promotion, punishment, trust and commitment as they affect knowledge workers in the construction industry and conclude as follows:

Pay: KW is an intrinsically enjoyable activity and pay should be used to reward what is done rather than compensate for doing it. KWrs should also be appreciated for their contribution to the organisation.

Praise: KWrs need the feedback on the quality and relevance of their performance, and information on what the organisation is doing and why.

Promotion: There is the need to develop progression that does not remove KWrs from their area of expertise, provide facilities and opportunities to grow and develop a culture of empowerment which promotes trust, commitment and devolution of various degrees of decision making power and responsibility.

Punishment: KWrs, take risks, and expect to learn from their mistakes rather than be criticised for them. The Theory X paradigm is not suitable. They recommend these disciplinary steps for KWrs: informal oral warning, 
formal warning and final written warnings. Dismissal should be transparently fair so as not to corrode morale, commitment and loyalty.

Trust: Since the output of KWrs are not easily measurable there is need to trust them and their judgment. This trust, affects the perception of knowledge worker's motives and impact directly on their commitment to the organisation.

Commitment: For KWrs, organizations should build commitment (a psychological bond) and, not compliance (externally imposed).

\subsubsection{Motivation of Engineering Staff in the Manufacturing Industry}

Petroni \& Colacino (2008) examine the motivational concerns of engineering staff in manufacturing industries and identify the three critical motivational factors as managerial policies and supervisory practices, appropriate managerial perception of engineers' status and role within the organization and job-related motivational mechanisms. With 376 responses from 11 engineering organizations in different sectors, they found that the issues of concern to the KWrs are inadequate reward system which favours managerial careers, inadequate understanding of engineers' expectations, failure to differentiate between professionals and other workers and inadequate managerial competence and knowledge.

They conclude that knowledge workers are a special kind of asset which increase in value over time and recommend inter alia, retraining, sabbatical leaves, rotation programs, powerful communication content of incentives and job redesigned which is in tandem with the Hackman and Oldham model and the findings of Cauger and Zawaki, 1983) discussed earlier.

\subsection{Effective Strategies for Motivating \& Retaining Knowledge Workers}

Horwitz et al. (2003:23) identified the following as the most effective strategies for attracting, motivating and retaining KWrs.

Table 3. Strategies to attract motivate \& retain knowledge workers

\begin{tabular}{|c|c|c|c|}
\hline Rank & Attract & Motivate & Retain \\
\hline $1^{\text {st }}$ & Very competitive package & Freedom to plan work & Challenging work \\
\hline $2^{\text {nd }}$ & Internal talent development & Challenging work & Highly competitive work \\
\hline $3^{\text {rd }}$ & $\begin{array}{l}\text { Reputation as employer of } \\
\text { choice }\end{array}$ & $\begin{array}{l}\text { Access to leading edge technology } \\
\text { and products }\end{array}$ & $\begin{array}{l}\text { High } \\
\text { incentive/bonus }\end{array}$ \\
\hline $4^{\text {th }}$ & $\begin{array}{l}\text { Use of proactive recruitment } \\
\text { initiatives }\end{array}$ & Top management support & $\begin{array}{l}\text { Opportunities to develop in a } \\
\text { specialist field }\end{array}$ \\
\hline $5^{\text {th }}$ & Advertised jobs & Ensuring fulfilling work & Top management support \\
\hline
\end{tabular}

Source: Human Resource Management Journal, Vol 13 No 4, 2003, p 28.

Note that most of the factors crisscrossed the three axes and that their rankings varied with the purpose. They also found that these variables and their effectiveness varied across industries

\subsection{Other Issues in Managing \& Motivating Knowledge Workers}

\subsubsection{The Allure of Intrinsic Rewards}

For KWrs intrinsic rewards are more effective. Thomas (2000) believes that intrinsic motivation depends on the extent to which the individual experiences the following 'senses' while working: sense of meaningfulness, sense of choice, sense of competence and sense of progress. He also proposes that there are appropriate sets of managerial practices to encourage intrinsic motivation through these four rewards.

Kretner \& Kinicki (2012) advise managers on how to achieve these intrinsic motivational states. Meaningfulness is achieved by inspiring and modeling; choice by empowering and delegating; competence by supporting and coaching and progress by monitoring and rewarding.

\subsection{Organising for Knowledge Work}

The management of KWrs demands appropriate structures and many successful enterprises are now organized to ensure that their professional intellect creates value. Novacare has a structure that frees its KWrs of administrative and business responsibilities and ensures that they are self-sufficient and tremendously autonomous on customer issues while functional specialists provide support the therapists. To do this 
successfully, it adopts the inverted organizational structure in which top management becomes a support structure and only intervenes in cases of extreme emergency (Quinn et al, 1996:71).

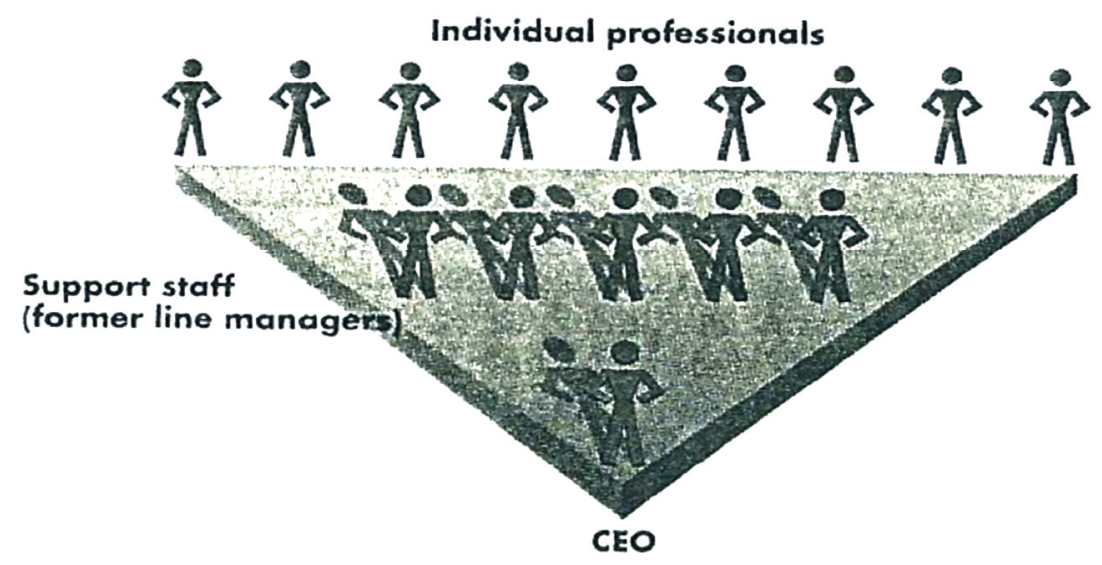

Figure 1. The inverted organization; field experts become bosses

Source: Quinn, J. B., Anderson, P., \& Finkelstein, S. (1996). Managing Professional Intellect: Making the Most of the Best. Harvard Business Review, March-April, p76.

This works when the experts embody most of the knowledge and can attend to patients independently. When the professionals need to collaborate with each other, the spider's web is adopted in which KWrs work with different colleagues as appropriate and this makes each spider's web unique in, patterns and power relations.

\subsubsection{Leadership}

Management of KWrs requires an environment for them to bloom so that they willingly transform tacit knowledge into explicit knowledge and participate with unquestionable commitment in moving the organization forward. KWrs want a high degree of protection, recognition and freedom to explore in an environment in which they contribute to the corporate success and be in charge of their lives. They also prefer a coach, enabler and a mentor as well as an organization where people feel bonded and not management by e-mail, voice mail and SMSs! (Wetlaufer, 2000). In this regard, Drucker (1967) opines that a KWr can only be helped but not micromanaged. Increasing their performance does not mean working harder; it means removing the obstacles to performance and channeling their efforts appropriately

This is thus a matter of influence and requires a style that fertilizes their talent, accommodates their preferred ways of working and enables them to appreciate their own contributions to organizational progress. This also requires recognition, clear objectives, opportunities for improvement and motivational patterns that are appropriate to each KWr. Certainly, knowledge workers do not require bosses but knowledge managers, who should reply convincingly to a simple question: Why should a knowledge worker want to be managed by you?

Beyond being knowledge managers, other issues in leading KWrs have been identified by Gofee \& Jones (2007) as:

- $\quad$ Protecting them from 'organizational rain'; those distracting rules and politics of big-budget activities. Representative bureaucracy should be the norm as against mock bureaucracy(where rules are ignored by all) or punishment-centered bureaucracy(where rules are imposed by one group on another)

- $\quad$ Encouraging diversity, recruiting stars and enabling such people to pursue private efforts because there are some direct and indirect payoffs( Google allows employees 1 day a week on start-up ideas) and let them recognize their interdependence.

- $\quad$ The leader should be a protective, benevolent guardian and allow KWrs the freedom.

4.6 Other Matters

The key difference in KWrs is their knowledge and their different attitudes to issues related to work. It must be 
admitted that the level of 'knowledgeness' varies but whatever the case, these issues are relevant across board to the KWRS.

- Tell them why. Knowledge workers must know why things are being done and in a certain way. Brown made this argument long before now (1964:218):

hiring men and women to work in complete ignorance of what they are doing, why they are doing it and for whom they are doing it is a preposterous anachronism and although people may be induced to join a firm by promises of high wages, good working conditions, pension schemes and all the usual paraphernalia of 'welfare'; they will only stay with the firm when it is able to satisfy their needs as human beings..

- See them as assets and manage them as partners. That is the way to keep them and retain the drain on intellectual capital.

- Since what motivates the KWr is the challenge and the sense of achievement he is fuelled by the need to see the results of his/her efforts and how he fits into the larger picture (Oboh, 2010:13).

- It is imperative to help knowledge workers to broaden their skill base(so as to be on top of their game); to publicly recognize their contributions, and achieve work-life flexibility and balance (Groysberg et al, 2004:92).

\section{Conclusion}

People are the most critical elements in the organization because they acquire and manage other resources. Human beings are however complex and unpredictable. The key challenge facing organizational chieftains is to ensure that their workers are able and willing to contribute commensurately to the achievement of organizations objectives. People go to work to meet their needs which vary with individuals, groups and over time. In trying to motivate people to work, organizations should do all it takes to ensure that people satisfy their different and varying needs as they work for the organizations. I entirely agree with McGregor (1960:49) who specifically asserts that management should create 'conditions such that members of the organization can achieve their own goals best by directing their efforts towards the success of the enterprise'. This is the only genuine route to motivation; other shortcuts will not work. This takes care of the willingness to work. But organizations also have to ensure that the people have the capacity to work and that they are empowered to work.

The emergence of KW/KWrs has fundamentally changed the equation. While the foregoing postulations are applicable to everybody, they become more critical for KWrs who, because of the value they bring to the table and their various characteristics, demand more from organizations than their colleagues. Furthermore, while most workers are now KWrs, the degree of 'knowledgeness' varies and the higher this degree, the more the peculiar strategies recommended in this paper become operative.

At the end of the day, whether knowledge or non-knowledge, every worker will appreciate to be respected, recognized, empowered and given relative freedom of choice to perform his/her duties. The only problem is that while others would wish for this scenario, the knowledge workers will insist on them and the organizations will have to oblige or bid good bye to its quest for competitive superiority in this knowledge economy.

\section{References}

Alvesson, M. (2000). Social identity and the problem of loyalty in knowledge-intensive companies. Journal of Management Studies, 37(8), 1101-1123. http://dx.doi.org/10.1111/1467-6486.00218

Babcock, P. (2005). Find out what the workers want. HR Magazine, 50(4), 51-57.

Blumberg, M., \& Pringle, D. C. (1982). The Missing Opportunity in Organizational Research; Some Implications for a Theory of Work Motivation. Academy of Management Review, 182, 560-569.

Brown, J. A. C. (1964). Social Psychology of Industry.

Caudron, S. (1995). Lessons from HR overseas. Personnel Journal, 88.

Couger, J. D., \& Zawacki, R. A. (1980). Motivating \& Managing the Computer Personnel. New York: John Wiley \& Sons.

Daft, R. L. (2010). New Era of Management (9th ed.). Australia: South-Western/Cengage Learning.

Davies, K. (1977). Human Behaviour At Work: Organisational Behaviour (5th ed.). New York: McGraw-Hill.

Drucker, P. (1989). The New Realities (1st ed.). Oxford: Heinemann.

Drucker, P. F. (1967). The Effective Executive. London: Pan Books/ Heinemann.

Drucker, P. F. (1991). The new productivity challenge. Harvard Business Review, 69-79. 
Drucker, P. F. (1993). Post-Capitalist Society. New York: Harper Business.

Drucker, P. F. (2002). Knowledge work. Executive Excellence, 19(10), 12.

Drucker, P. F. (2003). New trends in management. Executive Excellence, 20(8), 8-9.

Feldman, R. S. (2002). Understanding Psychology (6th ed). Boston: McGraw-Hill.

Gofee, R., \& Jones, G. (2007). Leading Clever People. Harvard Business Review, March, 72-79.

Granovetter, M. (1973). The strength of weak ties. American Journal of Sociology, 78, 1360-1380. http://dx.doi.org/10.1086/225469

Grant, R. M. (1996a). Prospering in dynamically-competitive environments: Organizational capability as knowledge integration. Organization Science, 7(4), 375-387. http://dx.doi.org/10.1287/orsc.7.4.375

Grant, R. M. (1996b). Toward a knowledge-based theory of the firm. Strategic Management Journal, 17, 109.

Grantham, C. E., \& Ware, C. (2007). What attracts knowledge workers? Work Design Collaborative.

Groysberg, B., Nanda, A., \& Nohria, N. (2004). The risky business of hiring stars. Harvard Business Review, May, 92-100.

Hackman, J. R. (1975). Is Job Enrichment Just A Fad? Harvard Business Review, 53.

Hackman, J. R., \& Oldham, G. R. (1975). Development of the Job Diagnostic Survey. Journal of Applied Psychology, 60(2), 159-170. http://dx.doi.org/10.1037/h0076546

Hackman, R. J., \& Oldham, G. R. (1976). Motivating through the design of work: test of a theory. Organisation Behaviour \& human Performance, 16, 250-279. http://dx.doi.org/10.1016/0030-5073(76)90016-7

Hackman, R. J., \& Oldham, G. R. (1980). Work Redesign. Reading, MA: Addison-Wesley.

Herzberg, F. (1968). One More Time: How Do You Motivate Employees. Harvard Business Review, January, $87-96$.

Howrtz, F. M., Heng, C. T., \& Quazi, H. A. (2003). Finders, keepers? Attracting, motivating and retaining knowledge workers. Human Resource Management Journal, 13(4), 23-44. http://dx.doi.org/10.1111/j.1748-8583.2003.tb00103.x

Huang, X., \& Van De Vliert, E. (2003). Where Intrinsic job satisfaction fails to work: National moderators of intrinsic moderation. Journal of Organisational Behaviour, 24, 159-179. http://dx.doi.org/10.1002/job.186

Ingo, F., \& Fiona, L. (2007). Cultural differences in motivating global knowledge workers. Equal Opportunities International, 26(8), 823-833. http://dx.doi.org/10.1108/02610150710836154

Ivancevich, J. M., \& Donelly, J. H. (1980). Managing For Performance. Dallas, Texas: Business Publications Inc.

Ivancevich, J. M., \& Matteson, M. (2002). Organisational Behaviour and Management. Boston: McGrawHill/Irwin.

Jayne, R. L. (2006). Knowledge Worker: Human Resource Strategy to Achieve a Competitive Advantage. St. Ambrose University, Davenport, Iowa 14 August.

Kreitner, R., \& Kinicki, A. (2012). Organisational Behaviour (10th ed.). Boston: McGraw Hill/Irwin.

Luthans, F. (2005). Organisational Behaviour (10th ed.). Boston: McGraw-Hill.

Maslow, A. H. (1943). The Theory of Human Motivation. Psychological Review, July, 370-396. http://dx.doi.org/10.1037/h0054346

McGregor, D. (1960). The Human Side of Enterprise. New York: Mcgraw-Hill Book Company.

Miner, J. B. (1999). Theories of Organisational Behaviour. Illinois: Dryden Press.

Mullins, L. J. (1996). Management and Organisational Behaviour. London: Pitman Publishing.

Muo, Ik. (1999). The Nature, Scope \& Challenges of Management. Lagos: Impressed Publishers.

Muo, Ik. (2007). Motivation in Complex Organisations. In Bello-Imam et al. (Eds.), Fundamentals of HRM in Nigeria. Ibadan: College Press \& Publishers.

Oboh, O. A. (2010). Motivating Nigerian Knowledge Workers. BusinessDay, September, 13. 
Olomolaiya, A., \& Egbu, C. (2004). Motivating Knowledge Workers: The Dilemma of HRM'S Contributions To KM in The Construction Industry. School of the Built and Natural Environment, Glasgow Caledonian University, Glasgow. G4 0BA, Scotland, UK.

Opashl, R. L., \& Dunnette, M. D. (1966). The Role Of Financial Compensation In Industrial Motivation. Psychological Bulletin, 66, 94-118. http://dx.doi.org/10.1037/h0023614

Petroni, A., \& Colacino, P. (2008). Motivation strategies for Knowledge Workers: Evidences \& Challenges. Journal of Technology Management \& http://dx.doi.org/10.4067/S0718-27242008000100003

Pfau, B., \& Kay, I. (2002). Playing The Training Game and Loosing. HR Magazine, August, 49-54.

Pink, D. (2005). A whole New Mind: Moving from the Information age to the conceptual age. Berkely Publishing group.

Quinn, J. B., Anderson, P., \& Finkelstein, S. (1996). Managing Professional Intellect: Making The Most of the Best. Harvard Business Review, Marc-April, 71-80.

Rue, L. W., \& Byars, L. L. (1977). Management Theory and Application. Homewood, Illinois: Richard D Irwin.

Serrat, O. (2008). Managing Knowledge Workers. Knowledge Solutions, October.

Thomas, K. (2000). Intrinsic Motivation at work: Building Energy \& Commitment. San-Francisco: Berret-Koehler.

Vogt, E. (1995). The nature of work in 2010. Telecommunications, 29, 21-27.

Ware, J., \& Grathan, C. (2007). What is a knowledge Worker; the Future of Work Agenda. The Work Design Collaborative.

Watson, W. (2001). Demographics and Destiny: Winning the War for Talent. Research Report.

Wetlaufer, S. (2000). Who Wants to Manage a Millionaire. Harvard Business Review, July-August, 53-60.

Yukl, G. (1990). Skills for Managers and Leaders. Upper Saddle River, New Jersey: Prentice Hall. 